\title{
General construction of lithiophilic 3D skeleton for dendrite-free lithium metal anode via a versatile MOF-derived route
}

\author{
Liyan Zeng, Ting Zhou, Xijun Xu, Fangkun Li, Jiadong Shen, Dechao Zhang, Jun Liu* and Min Zhu
}

\begin{abstract}
The pursuit of high-mileage models results in the recurrence of lithium metal batteries (LMBs) to researchers' horizon. However, the lithium ( $\mathrm{Li}$ ) metal anode for LMBs undergoes the uncontrollable formation of Li dendrites and infinite volume change during cycling, impeding its practical application. To overcome these challenges, we developed a metal-organic framework (MOF)-derived pathway to construct lithiophilic three-dimensional (3D) skeleton using different substrates (e.g., carbon cloth (CC) and Cu mesh) for dendrite-free lithium metal anodes. As a typical example, the MOF-derived $\mathrm{ZnO} /$ nitrogen-doped carbon (NC) nanosheet-modified 3D CC was well-constructed as a lithiophilic hierarchical host (CC@ZnO/NC@Li) for molten Li infiltration. Benefiting from the lithiophilic $\mathrm{N}$-functional groups and LiZn alloy, the synthesized CC@ZnO/NC@Li composite anode promoted the uniform distribution of $\mathbf{L i}$, resulting in a dendrite-free morphology. Meanwhile, the 3D conductive carbon skeleton enhanced the reaction kinetics and buffered the volume change of the electrode. The CC@ZnO/ NC@Li composite anode presented a prolonged lifespan of over 1000 cycles at $5 \mathrm{~mA} \mathrm{~cm}^{-2}$ with a low overpotential of $19 \mathrm{mV}$. Coupled with a $\mathrm{LiFePO}_{4}$ cathode, the $\mathrm{CC} @ \mathrm{ZnO} /$ NC@Li composite anode also exhibited superior electrochemical properties in the full-cell system. This versatile strategy may open up the channel of designing multi-functional lithiophilic 3D hosts for the Li metal anode.
\end{abstract}

Keywords: dendrite-free lithium anode, 3D lithiophilic host, MOF-derived, $\mathrm{ZnO} / \mathrm{NC}$ nanosheets, lithium metal batteries

\section{INTRODUCTION}

Since their discovery in the 1990s, the demand for commercial lithium ion batteries (LIBs) in energy storage devices has dramatically increased, and LIBs are now applied in a wide range of fields, such as electric vehicles, portable electronics, and aviation [1-4]. Meanwhile, given the confined theoretical specific capacity of graphite anode $\left(372 \mathrm{~mA} \mathrm{~h} \mathrm{~g}^{-1}\right)$, the increased rate in the energy density of LIBs is gradually lagging behind social needs [5]. Among the currently emerging anodes, the Li metal anode with a theoretical specific capacity of $3860 \mathrm{~mA} \mathrm{~h} \mathrm{~g}^{-1}$ is a promising contender; it can significantly raise the energy density of batteries and meet the $500 \mathrm{~W} \mathrm{~h} \mathrm{~kg}^{-1}$ design requirement for nextgeneration high-energy-density devices [6-9]. However, the Li metal anode normally has certain disadvantages. The "hostless" nature of lithium deposition can result in unstable solid electrical interface (SEI) films on the active lithium surface and infinite volume expansion during cycling, which will cause a series of issues, such as low coulombic efficiency (CE), poor cyclic stability, and safety hazard $[10,11]$. The appearance of dendrites in the irregular Li plating/stripping process may cause severe safety problems, thereby posing grave challenges for the commercialization of Li metal anodes [12,13].

A series of strategies have been exploited to settle the abovemotioned problems. The stabilization of SEI films by adding beneficial components to the electrolyte and the application of solid electrolytes with high elastic modulus can impede $\mathrm{Li}$ dendrites from penetrating the membrane and thus causing a short circuit [14-17]. Additionally, the introduction of a dense and stable artificial SEI film at the Li interface can inhibit the constant formation of $\mathrm{Li}$ dendrites to a certain extent [18-22]. Nevertheless, the aforementioned modifications did not effectively solve the problem of volume change in the Li electrode due to its "hostless" property.

Therefore, the construction of a three-dimensional (3D) stable "host" for Li metal is a promising strategy to simultaneously address the $\mathrm{Li}$ dendrite and infinite dimension change. The special $3 \mathrm{D}$ host provides a sufficient space to store $\mathrm{Li}$ and mitigate electrode size changes and possesses a high specific surface area for lowering the local current density and preventing the growth of $\mathrm{Li}$ dendrites [23,24]. To date, a series of 3D Li skeletons, such as 3D metal-based (e.g., Cu mesh (CM) [25-27], $\mathrm{Cu}$ nanowires [28,29], and $\mathrm{Cu}$ foam [30,31]) and carbon-based materials (e.g., carbon nanotubes [32], graphene [33], and carbon cloth (CC) [34]), have been exploited to effectively alleviate the double problems of volume change and Li dendrites in $\mathrm{Li}$ metal anodes. Among these 3D skeletons, CC is most promising due to its lightweight, high surface areas, superior mechanical properties, and good corrosion resistance.

Electrochemical deposition is widely used for Li prestorage, but its complex operation and uneven Li distribution during the electrodeposition process are not conducive for practical applications [35]. A molten Li infusion technology proposed by Lin et al. [33] can achieve high manufacturing efficiency and uniform $\mathrm{Li}$ distribution during the Li prestorage process. However, the hosts require sufficient lithiophilicity to induce the automatic absorption of molten $\mathrm{Li}$ and maintain a low $\mathrm{Li}$ nucleation barrier during cycling. The challenge is that most $3 \mathrm{D}$ skeletons, except

School of Materials Science and Engineering and Guangdong Provincial Key Laboratory of Advanced Energy Storage Materials, South China University of Technology, Guangzhou 510641, China

* Corresponding author (email: msjliu@scut.edu.cn) 
for reduced graphene oxide, cannot meet these requirements. Therefore, appropriate surface modification strategies must be explored to significantly enhance the affinity between the Li and $3 \mathrm{D}$ skeletons. The decoration of 3D skeletons with lithiophilic substances is one of the most effective ways, and a reasonable design of micro/nanostructured lithiophilic layer on 3D skeletons facilitates the improvement of the wettability of Li metals, resulting in uniform Li deposition [36-40]. The present metalorganic framework (MOF)-derived pathway is an effective strategy to grow controllable hollow/porous structures and easily introduce lithiophilic $\mathrm{N}$-functional groups or precursors for the conversion to lithiophilic metal oxides [41-43]. Therefore, using the MOF-derived method to construct a tunable microstructured lithiophilic layer on the $3 \mathrm{D}$ skeleton is a promising approach to prepare dendritic-free lithium composite anodes.

Herein, CC modified with $\mathrm{ZnO}$ nanosheets and nitrogendoped carbon (CC@ZnO/NC) was first synthesized as an example and employed as the $3 \mathrm{D}$ skeleton to accommodate molten $\mathrm{Li}$ for the dendrite-free composite $\mathrm{Li}$ anode. With the synergistic effect of the induced lithiophilic $\mathrm{ZnO}$ and $\mathrm{N}$-doped carbon, CC@ZnO/NC skeleton possessed high Li affinity to realize the rapid infusion of molten $\mathrm{Li}$ into the host forming a dense CC@ZnO/NC@Li composite anode. Furthermore, the flexible 3D framework structure of CC served as a soft snubber to mitigate the dimension change of the anode during cycling. In addition, the LiZn alloy obtained via the chemical reaction of $\mathrm{ZnO}$ and $\mathrm{Li}$ can facilitate electron/ion diffusion and regulate $\mathrm{Li}$ in uniform plating/stripping. Given the above-mentioned merits, the synthetic CC@ZnO/NC@Li composite anode presented a prolonged lifetime with a low hysteresis voltage, and its skeleton exhibited a high $\mathrm{CE}$ after long cycling. Furthermore, the CC@ZnO/NC@Li||LiFePO 4 (LFP) full cells also achieved an improved cycling performance and rate capability.

\section{EXPERIMENTAL SECTION}

\section{Fabrication of CC@ZnO/NC@Li composite anode}

First, 2-methylimidazole $\left(0.4 \mathrm{~mol} \mathrm{~L}^{-1}\right)$ and $\mathrm{Zn}\left(\mathrm{NO}_{3}\right)_{2} \cdot 6 \mathrm{H}_{2} \mathrm{O}$ $\left(0.05 \mathrm{~mol} \mathrm{~L}^{-1}\right)$ were mixed in $80 \mathrm{~mL}$ of ultra-pure water to form a uniformly mixed white suspension. Then, a piece of CC $(4 \mathrm{~cm} \times$ $5 \mathrm{~cm}$ ) was immersed in this mixture for $6 \mathrm{~h}$ to in-situ grow $\mathrm{Zn}$ organic framework nanosheets (ZIF-L) on the CC. Then, the CC was removed, cleaned with ultra-pure water, and dried overnight at $80^{\circ} \mathrm{C}$. The CC@ZnO/NC was obtained by heating CC@ZIF-L in a muffle furnace at $400^{\circ} \mathrm{C}$ for $1 \mathrm{~h}$ at a ramp rate of $1^{\circ} \mathrm{C} \mathrm{min}{ }^{-1}$. Finally, the CC@ZnO/NC@Li composite anode was fabricated by infusing molten $\mathrm{Li}$ into the lithiophilic CC@ZnO/NC skeleton at $320^{\circ} \mathrm{C}$.

Fabrication of 3D CM decorated with MOF-derived NC nanowire array (CM/NC NWA)@Li composite anode

$\mathrm{CM} / \mathrm{NC}$ NWA was prepared by a similar $\mathrm{Cu}-\mathrm{MOF}$-derived method. First, a clean CM $(3.5 \mathrm{~cm} \times 4.5 \mathrm{~cm})$ was immersed in $20 \mathrm{~mL}$ of 7,7,8,8-tetracyanobenzoquinodimethane (TCNQ, $0.2 \mathrm{mmol} \mathrm{L}^{-1}$ ) acetonitrile solution for $24 \mathrm{~h}$ to in-situ grow $\mathrm{Cu}$ MOF on the CM (CM/Cu-MOF). Then, the CM was removed, cleaned with acetonitrile and anhydrous ethanol, and vacuum dried at $50^{\circ} \mathrm{C}$. The $\mathrm{CM} / \mathrm{NC}$ NWA was obtained by annealing the $\mathrm{CM} / \mathrm{Cu}-\mathrm{MOF}$ precursor at $400^{\circ} \mathrm{C}$ for $2 \mathrm{~h}$ with a heating rate of $2^{\circ} \mathrm{C} \min ^{-1}$ under argon atmosphere. Finally, the $\mathrm{CM} / \mathrm{NC}$ NWA@Li composite anode was fabricated by electrodepositing
Li metal with $10 \mathrm{~mA} \mathrm{hm}^{-2}$ capacity into the CM/NC NWA skeleton.

\section{Characterization}

The morphological characteristic and element distribution were explored via field emission scanning electron microscopy (SEM; Carl Zeiss Supra 40) and transmission electron microscopy (TEM; F200x, Talos). X-ray diffraction (XRD) was used to identify the material composition, and crystal phases were collected on PANalytical Empyrean. The chemical bonding states of the samples were detected through X-ray photoelectron spectroscopy (XPS; Thermo Scientific).

\section{Electrochemical measurements}

Coin cells tests were performed with CR2016-type coin cells, and polypropylene film (Celgard 2400) was used as the separator in all cells. For half cells, Cu foil, CC@ZnO/NC, and CM/NC NWA were applied as working electrodes to pair with the bare Li foil electrode. For symmetrical cells, bare Li foil, CC@ZnO/NC@Li, and CM/NC NWA@Li were applied as working electrodes. $\mathrm{CF}_{3} \mathrm{SO}_{2} \mathrm{NLiSO}_{2} \mathrm{CF}_{3}$ (LiTFSI) $\left(1 \mathrm{~mol} \mathrm{~L}^{-1}\right)$ in 1,3-dioxolane (DOL)/ dimethoxyethane (DME) $(1: 1, v / v)$ with $2 \mathrm{wt} \% \mathrm{LiNO}_{3}$ was selected as the electrolyte for the half and symmetrical cells. Galvanostatic cycling tests were performed on a LAND (CT2001A) testing system. Electrochemical impedance spectroscopy (EIS) measurements were conducted on a Gamry Interface 1000 electrochemical workstation at the frequency range of $0.01-10^{5} \mathrm{~Hz}$. For Li||LFP full cells, bare Li foil, CC@ZnO/ NC@Li, and CM/NC NWA@Li composite anodes were paired with LFP cathodes $\left(\sim 1.3 \mathrm{mg} \mathrm{cm}^{-2}\right)$, and the commercial $1 \mathrm{~mol} \mathrm{~L}^{-1}$ $\mathrm{LiPF}_{6}$ in ethylene carbonate/dimethyl carbonate $(1: 1, v / v)$ was employed as the electrolyte. The test voltage range for coin full cells was 2.0-4.0 V, and that for the flexible CC@ZnO/NC@Lil| LFP pouch cell was $2.5-4.2 \mathrm{~V}$.

\section{RESULTS AND DISCUSSION}

Fig. 1a shows the detailed process diagram of CC@ZnO/NC@Li. First, ZIF-L were uniformly grown on the CC by a facile water bath deposition. Then, the uniform ZIF-L-decorated CC was annealed in air to obtain the lithiophilic CC@ZnO/NC host. Finally, the CC@ZnO/NC host was infused with molten lithium to form the CC@ZnO/NC@Li composite anode. The morphology of the CC@ZIF-L precursor and the derived CC@ZnO/NC intermediate were measured via SEM. The ZIF-L appeared as uniform nanosheets and grew perpendicularly on the surface of $\mathrm{CC}$ to form a self-supported nanoarray structure (Fig. 1b). After the growth of ZIF-L, the color of the CC skeleton turned light gray (Fig. S1), but the flexibility of the CC skeleton was not affected. Further, the XRD result of CC@ZIF-L (Fig. S2) agreed with the standard ZIF-L sample in previous literature [44], confirming the successful synthesis of ZIF-L on the CC. Moreover, the XRD pattern of the annealed CC@ZIF-L precursor (Fig. 1d) was in accordance with the $\mathrm{ZnO}$ standard PDF card (ICSD 06-5119), except a bulge diffraction peak that originated from CC, which indicates that the lithiophilic CC@ZnO/NC was successfully obtained. Fig. 1c shows that CC@ZnO/NC well inherited the interconnected nanosheet structure of the ZIF-L precursor. The TEM image (Fig. 1e) illustrates that a single $\mathrm{ZnO} /$ NC nanosheet was composed of numerous ultrafine nanoparticles embedded in the carbon framework. The high-resolution TEM image (Fig. 1f) exhibits lattice spacings of 0.247 and 



Figure 1 (a) Flow chart for the preparation of CC@ZnO/NC@Li composite anode; SEM images of (b) CC@ZIF-L and (c) CC@ZnO/NC; (d) XRD pattern of $\mathrm{CC} @ \mathrm{ZnO} / \mathrm{NC}$; (e, f) TEM images and (g) the corresponding elemental mapping signals of $\mathrm{ZnO} / \mathrm{NC}$.

$0.281 \mathrm{~nm}$ on the nanoparticles, which can be assigned to the (101) and (100) planes of cubic $\mathrm{ZnO}$, respectively, and all nanoparticles were connected by the amorphous carbon originating from the pyrolytic organic groups. The TEM elemental mapping signals of $\mathrm{ZnO} / \mathrm{NC}$ nanosheet (Fig. $1 \mathrm{~g}$ and Fig. S3) demonstrate the co-existence and homogeneous distribution of $\mathrm{Zn}, \mathrm{O}, \mathrm{C}$, and $\mathrm{N}$, revealing that a considerable amount of $\mathrm{N}$ doped carbon was present in the $\mathrm{ZnO} / \mathrm{NC}$ nanosheet. The XPS results are provided in Figs S4 and S5. The XPS spectrum of Zn 2p (Fig. S5a) exhibits two typical signal peaks at 1022.5 and $1045.8 \mathrm{eV}$, belonging to $\mathrm{Zn} 2 \mathrm{p}_{3 / 2}$ and $\mathrm{Zn} 2 \mathrm{p}_{1 / 2}$, respectively. The XPS spectrum of $\mathrm{O} 1 \mathrm{~s}$ (Fig. S5c) reveals the presence of $\mathrm{Zn}-\mathrm{O}$, which further verifies the complete conversion of ZIF-L to $\mathrm{ZnO}$. Moreover, the peaks at $284.4,285.2$, and $285.9 \mathrm{eV}$ in the $\mathrm{C} 1 \mathrm{~s}$ XPS spectrum confirm the existence of $\mathrm{C}-\mathrm{C}, \mathrm{C}-\mathrm{N}$, and $\mathrm{C}-\mathrm{O}-\mathrm{C}$ (Fig. S5b), respectively. Meanwhile, the peaks at 398.3, 399.3, and $400.2 \mathrm{eV}$ in the $\mathrm{N} 1 \mathrm{~s}$ XPS spectrum (Fig. S5d) correspond to the doping of $\mathrm{N}$ elements in the carbon substrate in the form of pyridinic, pyrrolic, and graphitic $\mathrm{N}$, respectively. The $\mathrm{N}$-doped carbon was lithiophilic and strongly bonded to Li $[45,46]$. Thus, this modified 3D CC combines the strong synergistic of lithiophilic $\mathrm{ZnO}$ nanoparticles and $\mathrm{N}$-doped sites, which might promote the rapid and even adsorption of molten Li liquid on the CC@ZnO/NC skeleton.

Fig. 2a shows the detailed process of melting and entrapping Li onto CC@ZnO/NC skeleton. The molten Li metal gradually covered the CC@ZnO/NC skeleton, and the color of the skeleton changed to shiny silver. For a more accurate and intuitive observation, a video clip of the lithium entrapment process was offered. As presented in Movie S1, once the edge of the CC@ZnO/NC skeleton was immersed in molten Li, the liquid Li rapidly and automatically adsorbed onto the host along the skeleton network. After $5 \mathrm{~s}$, the whole CC@ZnO/NC skeleton was completely covered with the silver-colored molten $\mathrm{Li}$ (Fig. 2a and Fig. S6). However, in the contrast experiment of the $\mathrm{CC}$, the molten $\mathrm{Li}$ cannot be adsorbed on the CC skeleton (Movie S2), which strongly verifies that the MOF-derived $\mathrm{ZnO} /$ NC nanosheets significantly improve the lithiophilicity of the 


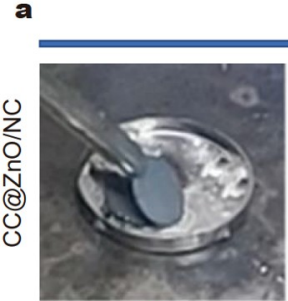

$1 \mathrm{~s}$

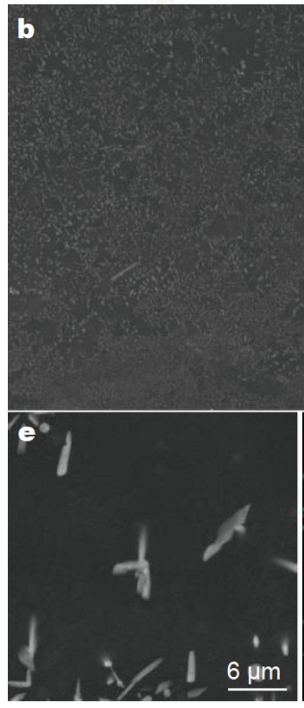

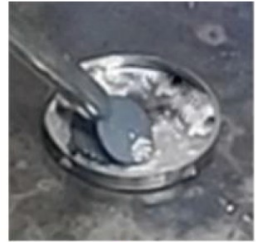

2s

Molten Li infusion

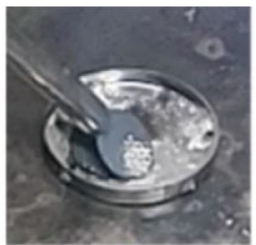

$3 \mathrm{~s}$

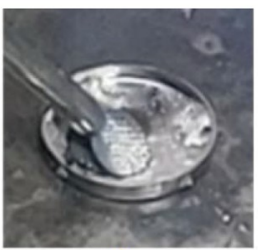

$4 \mathrm{~s}$

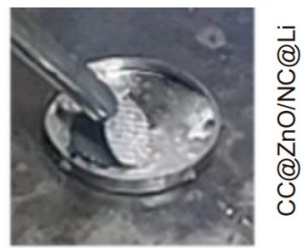

$5 \mathrm{~s}$
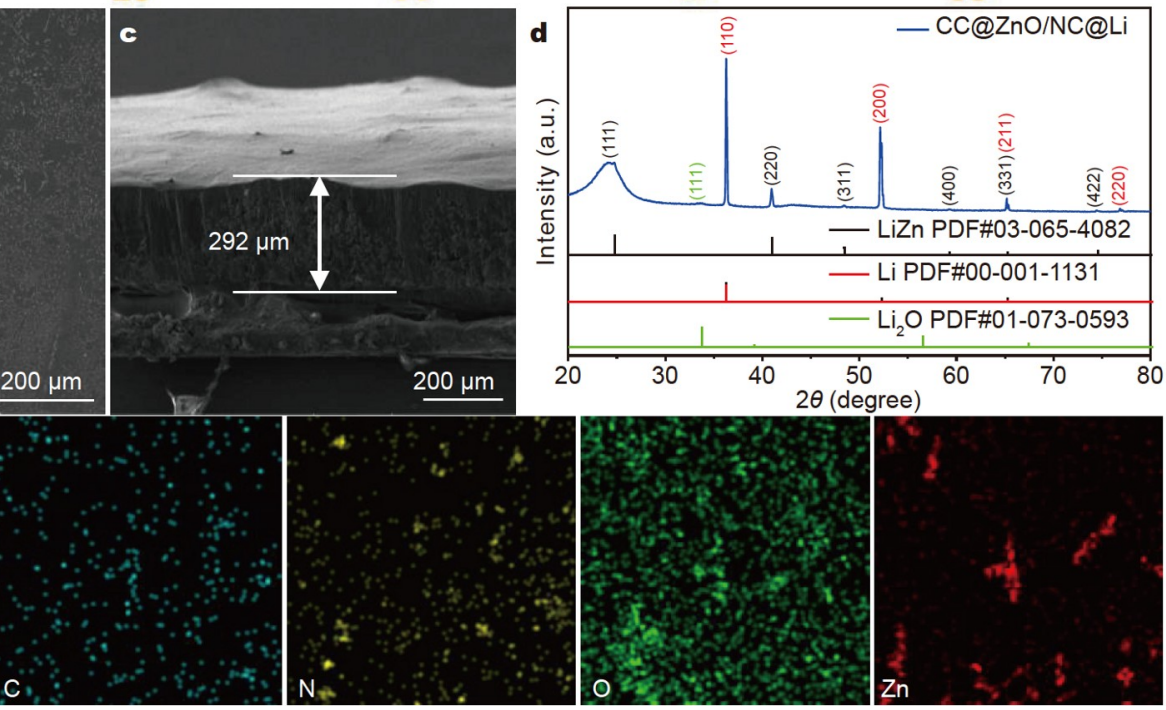

Figure 2 (a) Photographs of the infusion of molten Li into the CC@ZnO/NC (within $5 \mathrm{~s}$ ); (b, c) SEM images, (d) XRD pattern, and (e) SEM-energy dispersive spectroscopy elemental mapping images of CC@ZnO/NC@Li.

CC skeleton. Fig. 2 illustrates the morphology of CC@ZnO/ NC@Li. Evidently, the surface of the CC@ZnO/NC@Li composite anode is smooth, and the thickness of the Li metal is $\sim 292 \mu \mathrm{m}$. A mass of white particles appeared on CC@ZnO/ NC@Li. This phenomenon was further investigated via elemental mapping (Fig. 2e), and the results confirmed that this white-particle region was enriched with $\mathrm{Zn}$ element. The XRD pattern of CC@ZnO/NC@Li (Fig. 2d) verifies the formation of LiZn alloy after entrapment of Li metal. Thus, the white particles may be identified as LiZn alloy, which was formed because of the reaction between molten $\mathrm{Li}$ and $\mathrm{ZnO}$ during the entrapment process. The LiZn alloy particles facilitate the diffusion of $\mathrm{Li}$ metal and electrons, given that the potential difference between Li metal and LiZn alloy can provide a driving force for lithium diffusion, thus inducing the uniform dissolution and deposition of lithium [47]. In addition, the XPS result of CC@ZnO/NC@Li identifies the presence of $\mathrm{Li}, \mathrm{Zn}, \mathrm{C}$, O, and $\mathrm{N}$ elements (Fig. S7). The high-resolution spectrum of Li $1 \mathrm{~s}$ can be divided into three different signal peaks, which were located at 54.9 (Li), 55.3 $\left(\mathrm{LiCO}_{3}\right.$ or $\left.\mathrm{LiN}_{3}\right)$, and $55.9 \mathrm{eV}\left(\mathrm{Li}_{2} \mathrm{O}\right)[28,45]$. Therefore, except for $\mathrm{LiZn}$, lithium compounds, such as $\mathrm{LiCO}_{3} / \mathrm{LiN}_{3}$ and $\mathrm{Li}_{2} \mathrm{O}$, were observed in CC@ZnO/NC@Li. The areal mass loading and the mass ratio of Li on the CC@ZnO/NC@Li composite anode were about $13.5 \mathrm{mg} \mathrm{cm}^{-2}$ and $51.9 \%$, respectively, corresponding to a high areal capacity of $53.8 \mathrm{~mA} \mathrm{~h} \mathrm{~cm}^{-2}$ and a specific capacity of $2001.5 \mathrm{~mA} \mathrm{~h} \mathrm{~g}^{-1}$ (Table S1). Distinctly, this CC@ZnO/ NC@Li composite anode possesses a higher mass loading than the commercial Li disk $\left(21.7 \mathrm{mg} \mathrm{cm}^{-2}\right)$ accompanied by sufficient flexibility and binder-free features, which are promising for applications in flexible high-energy-density batteries.
To explore whether the CC@ZnO/NC@Li composite anode can maintain stable Li stripping/plating and inhibit the formation of lithium dendrites, we characterized the electrodes at different stripping/plating stages disassembled from symmetric cells using ex-situ SEM measurements. Fig. 3 displays the surface morphological change in CC@ZnO/NC@Li. When stripped with $20 \mathrm{~mA} \mathrm{~h} \mathrm{~cm}{ }^{-2}$ capacity of $\mathrm{Li}$, the originally filled molten $\mathrm{Li}$ was largely peeled off, and the spaces among carbon fibers reappeared (Fig. 3a). After the initial stripping process, Li was replated with $5 \mathrm{~mA} \mathrm{~h} \mathrm{~cm}^{-2}$ capacity, and the corresponding SEM image is displayed in Fig. 3b. Li filled the free space between CC fibers. With the plating capacity raised to $10 \mathrm{~mA} \mathrm{~h} \mathrm{~cm}^{-2}$ (Fig. 3c), the deposited Li appeared on the surface of the CC. With the continuous increase in the $\mathrm{Li}$ deposition capacity to $20 \mathrm{~mA} \mathrm{~h} \mathrm{~cm}^{-2}$ (Fig. 3d), the CC was completely covered with $\mathrm{Li}$ metal, and a dense surface reemerged without dendrites. These results confirm that the CC@ZnO/NC@Li composite anode effectively confines the deposition behavior of Li and guides the uniform plating of $\mathrm{Li}$ on its skeleton, thereby avoiding the formation of Li dendrites.

In the assessment of the cyclic property of the CC@ $\mathrm{ZnO} /$ NC@Li composite anode, SEM characterizations of the CC@ZnO/NC@Li and bare Li electrodes before and after cycling were carefully performed. As shown in Fig. $3 \mathrm{e}-\mathrm{h}$, the bare Li foil had a smooth surface and cross-section before cycling. However, after 100 cycles at $2 \mathrm{~mA} \mathrm{~cm}^{-2}$, the island-like $\mathrm{Li}$ dendrites unevenly piled up on the surface, and evident cracks and local $\mathrm{Li}$ pulverization emerged on the surface (Fig. 3i-l and Fig. S8). The cross-sectional SEM images (Fig. $3 \mathrm{~g}, \mathrm{~h}, \mathrm{k}$, and l) reveal that the initially flat surface of the $\mathrm{Li}$ foil became undulated, and a 


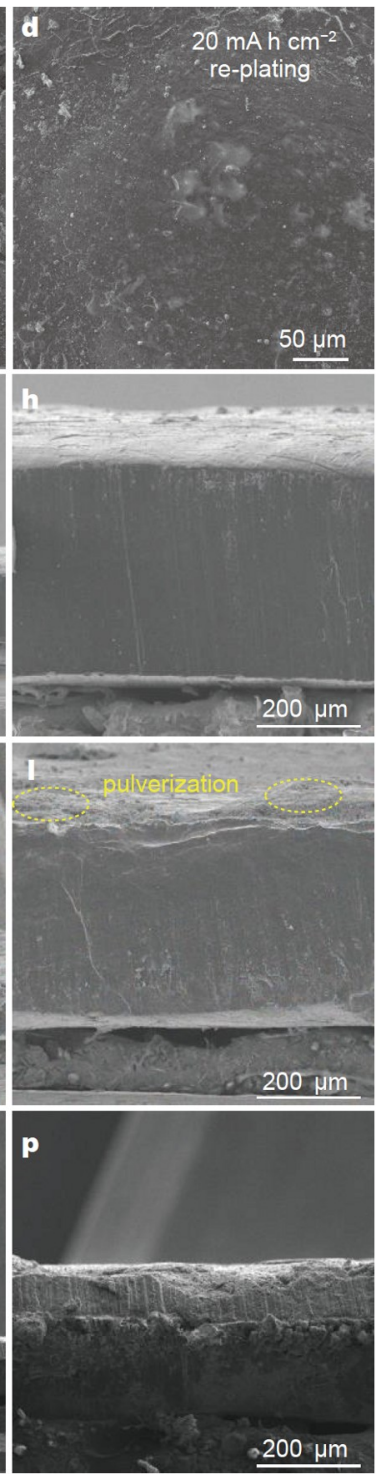

Figure 3 SEM images of the CC@ZnO/NC@Li electrodes in half cells after Li stripping to a capacity of (a) $20 \mathrm{~mA} \mathrm{~h} \mathrm{~cm}^{-2}$ and re-plating to capacities of (b) 5, (c) 10 , and (d) $20 \mathrm{~mA} \mathrm{~h} \mathrm{~cm}^{-2}$ at $1 \mathrm{~mA} \mathrm{~cm}^{-2}$; top-view and cross-sectional SEM images of bare Li electrode (e-h) before cycling and (i-1) after $100 \mathrm{cycles}$ at $2 \mathrm{~mA} \mathrm{~cm}^{-2}$ with $1 \mathrm{~mA} \mathrm{~h} \mathrm{~cm}^{-2}$; (m-p) top-view and cross-sectional SEM images of the CC@ZnO/NC@Li electrodes after 100 cycles at $2 \mathrm{mAcm}{ }^{-2}$ with the stripping/plating capacity of $1 \mathrm{~mA} \mathrm{~h} \mathrm{~cm}^{-2}$.

considerable amount of dead lithium accumulated on the surface, which seriously aggravated the pulverization and resulted in the increased thickness of bare Li from 395 to $450 \mu \mathrm{m}$. The formation of $\mathrm{Li}$ dendrites and Li pulverization were primarily responsible for the low $\mathrm{CE}$ and high interface resistance during the cycle [48]. The CC@ZnO/NC@Li electrode can still preserve a flat surface without significant changes in thickness after 100 cycles at $2 \mathrm{~mA} \mathrm{~cm}^{-2}$ (Fig. $3 \mathrm{~m}-\mathrm{p}$ ), which proves that the CC@ZnO/NC@Li composite electrode has superior structural robustness without Li dendrite and undergoes less dimension change after cycling. Based on the aforementioned analysis, the proposed lithiophilic $\mathrm{ZnO} / \mathrm{NC}$ nanosheet decorating strategy significantly improves the electrochemical performance of the CC@ZnO/NC@Li electrode.

The CC@ZnO/NC@Li and bare Li electrodes were assembled into symmetric cells to further evaluate the cycling stability and fluctuation of the overpotential via galvanostatic charge/discharge measurement. Fig. 4a presents the voltage-time curves of the CC@ZnO/NC@Li and bare Li electrode cycling at $2 \mathrm{~mA} \mathrm{~cm}{ }^{-2}$ with a cyclic capacity of $1 \mathrm{~mA} \mathrm{~h} \mathrm{~cm}{ }^{-2}$. The CC@ZnO/NC@Li electrode presented good cyclic stability with a lower overpotential than pure $\mathrm{Li}$ foil. The overpotential of CC@ZnO/ NC@Li was $\sim 29 \mathrm{mV}$ (5th)-17 mV (500th), which is considerably lower than that of the bare $\mathrm{Li}$ electrode $(38 \mathrm{mV}$ (5th) $-74 \mathrm{mV}$ (500th), Fig. S9), indicating that a large amount of Li dendrites accumulated upon cycling and increased the internal resistance of the bare $\mathrm{Li} / / \mathrm{Li}$ symmetric cell [49]. Additionally, the bare $\mathrm{Li}$ electrode displayed an evident voltage fluctuation compared with CC@ZnO/NC@Li in symmetric cells, indicating that the induction of lithiophilic $\mathrm{ZnO} / \mathrm{NC}$ nanosheets favors the formation of the stable SEI film [50]. Due to the unique design of lithiophilic ZnO/NC, the CC@ZnO/NC@Li underwent uniform Li plating/stripping during the cycling process, thus inhibiting the deposition of Li dendrites and stabilizing the SEI film. Therefore, the CC@ZnO/NC@Li electrode achieved a stable cycling performance over $1000 \mathrm{~h}$ and possessed an ultra-low 



g
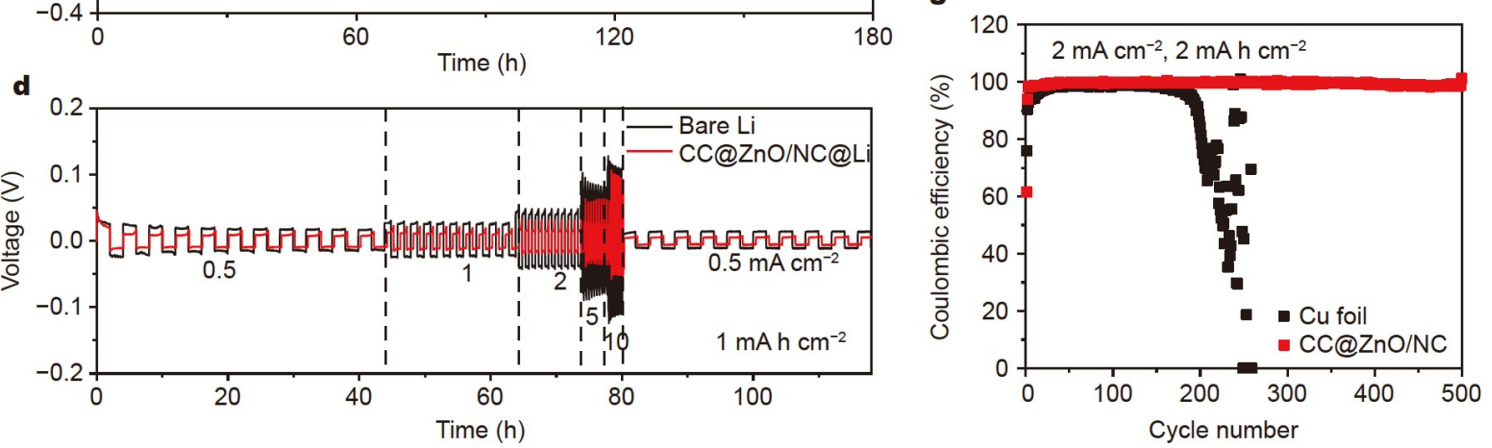

Figure 4 Electrochemical performance comparison of the bare Li (black) and CC@ZnO/NC@Li (red) symmetric cells: galvanostatic discharge/charge profiles at (a) 2, (b) 5 , and (c) $10 \mathrm{~mA} \mathrm{~cm}^{-2}$ with a fixed Li capacity of $1 \mathrm{~mA} \mathrm{~h} \mathrm{~cm}^{-2}$; (d) rate performances at different current densities; Nyquist plots (e) before cycling and (f) after 100 cycles at $2 \mathrm{~mA} \mathrm{~cm}^{-2}$ and $1 \mathrm{~mA} \mathrm{hm}^{-2}$; (g) CE of CC@ZnO/NC and Cu foil cycled at $2 \mathrm{~mA} \mathrm{~cm}^{-2}$ and $2 \mathrm{mAhcm}^{-2}$.

voltage hysteresis of $\sim 16 \mathrm{mV}$ without evident fluctuation. Furthermore, for the comprehensive assessment of the stability of the CC@ZnO/NC@Li electrode, the cyclic property was evaluated at high current densities of 5 and $10 \mathrm{~mA} \mathrm{~cm}^{-2}$ with a fixed capacity of $1 \mathrm{~mA} \mathrm{~h} \mathrm{~cm}^{-2}$ (Fig. $4 \mathrm{~b}, \mathrm{c}$, and Fig. S10). With the augmented current density, the CC@ZnO/NC@Li and bare Li electrodes showed an increasing trend in overpotential, indicating that the Li plating/stripping process occurred unevenly under high current densities [51]. The overpotential of the bare Li electrode gradually increased to $\sim 187 \mathrm{mV}$ (at $5 \mathrm{~mA} \mathrm{~cm}^{-2}$ ) and $\sim 216 \mathrm{mV}$ (at $10 \mathrm{~mA} \mathrm{~cm}^{-2}$ ) and was accompanied by fluctuating overpotential curves in the first several cycles (Fig. S11). On the contrary, the overpotential of the CC@ZnO/NC@Li electrode was $19 \mathrm{mV}$ (at $5 \mathrm{~mA} \mathrm{~cm}^{-2}$ ) and $90 \mathrm{mV}$ (at $10 \mathrm{~mA} \mathrm{~cm}^{-2}$ ), but maintained a stable similar cycling performance compared with that at lower current density $\left(2 \mathrm{~mA} \mathrm{~cm}^{-2}\right)$. All the above results demonstrate that the CC@ZnO/NC@Li electrode achieves a low electrochemical polarization and stable cyclic property with negligible fluctuation at high current densities. When the plat- ing/stripping capacity was increased to $5 \mathrm{~mA} \mathrm{~h} \mathrm{~cm}^{-2}$, the CC@ZnO/NC@Li electrode can still stably run over $800 \mathrm{~h}$ (Fig. S12). The CC@ZnO/NC@Li electrode exhibited the low overpotentials of $17,20,31,60$, and $98 \mathrm{mV}$ at the current densities of $0.5,1,2,5$, and $10 \mathrm{~mA} \mathrm{~cm}^{-2}$, respectively (Fig. 4d). The rate capability of the CC@ZnO/NC@Li electrode was also better than that of the bare $\mathrm{Li}$ electrode. The overpotential of the $\mathrm{Li}$ electrode was related to the $\mathrm{Li}$ dendrites formed by uneven $\mathrm{Li}$ plating/stripping and associated with the electrode pulverization due to the accumulation of loose "dead Li" at the same current densities [52]. The CC@ZnO/NC@Li electrode with MOFderived lithiophilic skeleton has several characteristics, such as a large specific surface area, extensive $\mathrm{N}$-doped active sites, and high lithiophilicity, which facilitate the uniform distribution of $\mathrm{Li}$ in the electrode, suppress the formation of Li dendrites, and alleviate volume expansion, thereby obtaining excellent electrochemical performance, which is better than that of the bare $\mathrm{Li}$ and other reported $\mathrm{ZnO}$-decorated $\mathrm{Li}$ electrodes (Table S2). These outstanding electrochemical results prove that the $\mathrm{Li}$ 
metal anode was significantly improved by adopting a ZIF-Lderived method to grow lithiophilic $\mathrm{ZnO} / \mathrm{NC}$ nanosheets on $\mathrm{CC}$ and form a hierarchical CC@ZnO/NC@Li.

For further exploration of the dynamic behavior of the CC@ZnO/NC@Li electrode, EIS test was conducted for the CC@ZnO/NC@Li and bare Li electrodes before and after 100 cycles (Fig. 4e, f). Fig. S13 illustrates the equivalent circuit. The first semicircle in the high-frequency range was used to estimate the SEI interfacial resistance $\left(R_{\mathrm{f}}\right)$, and a low interfacial resistance means that the electrode has a stable interface that can facilitate fast ion transport at the interface. Before cycling, given the highly reactive nature of $\mathrm{Li}$, a native SEI layer formed on the surface of the Li anode surface in contact with the electrolyte. After 100 cycles, the interfacial resistance of the bare Li electrode decreased from $\sim 46$ to $\sim 8 \Omega$, probably due to the rupture of the SEI layer and formation of lithium dendrites, which greatly increased the working surface area of the Li metal [53]. However, the CC@ZnO/NC@Li composite anode consistently presented low $R_{\mathrm{f}}$ values before and after cycling, $\sim 31 \Omega$ before cycling and $\sim 5 \Omega$ after 100 cycles, demonstrating that CC@ZnO/ NC@Li possessed desirable interfacial stability. In addition, the charge-transfer resistance $\left(R_{\mathrm{ct}}\right)$ of CC@ZnO/NC@Li was lower than that of the bare Li before cycling and after 100 cycles, which illustrates that the unique design of the CC@ZnO/NC@Li electrode reduced the continuous interface reaction and formed a stable SEI film to achieve a low charge-transfer resistance at the electrode-electrolyte interface. $\mathrm{CE}$ is also a vital argument related to the reversibility of the repeated Li plating/stripping, and it was measured in half cells ( $\mathrm{Li} v s$. CC@ZnO/NC and $\mathrm{Cu}$ foil) at $2 \mathrm{~mA} \mathrm{~h} \mathrm{~cm}^{-2}$ and $2 \mathrm{~mA} \mathrm{~cm}^{-2}$ with the charging cutoff voltage of $1 \mathrm{~V}$. As shown in Fig. 4g, the initial CE of CC@ZnO/NC (61.6\%) was lower than that of $\mathrm{Cu}$ foil $(76.0 \%)$, which may be ascribed to the reaction of lithiophilic $\mathrm{ZnO}$ nanosheets with the deposited $\mathrm{Li}$, forming the irreversible $\mathrm{Li}_{2} \mathrm{O}$ and then consuming a superfluous amount of Li. Subsequently, the CE of CC@ZnO/NC rapidly increased to $94.0 \%$ in the $2^{\text {nd }}$ cycle, exceeding the $\mathrm{CE}$ of $\mathrm{Cu}$ foil $(90.4 \%)$. The average CE of CC@ZnO/NC remained around $99.7 \%$ for over 500 cycles, whereas the $\mathrm{CE}$ of $\mathrm{Cu}$ foil dropped sharply after 200 cycles. This result proves that the CC@ZnO/NC skeleton can promote beneficial effects on stabilizing Li plating/stripping processes to improve cyclic reversibility.

In addition, to demonstrate the universality for modifying the $3 \mathrm{D}$ host with an MOF-derived approach, we investigated metalbased 3D CM/NC NWA as the host for Li prestorage. Fig. 5a exhibits the detailed MOF-derived morphology-inheritance process. The SEM images in Fig. 5b-d were used to explore the morphological evolution of the surface of CM. Fig. 5c indicates that the $\mathrm{Cu}-\mathrm{MOF}$ precursor rooted from the $3 \mathrm{D}$ interconnected CM exhibited a uniform structure of NWA. After annealing, the



Figure 5 (a) Schematic of the construction procedure of CM/NC NWA; SEM images of (b) pristine CM, (c) CM/Cu-MOF, and (d) CM/NC NWA; (e) optical image and (f) XRD patterns of CM, CM/Cu-MOF, and CM/NC NWA; (g) high-resolution N 1s XPS spectrum of CM/NC NWA. 
$\mathrm{CM} / \mathrm{NC}$ NWA well inherited the NWA structure of the CuMOF precursor with several cross-linked nanowires. The surface modification of CM can also be judged by the corresponding color change of CM (Fig. 5e), that is, the color changed from the initially purplish red to light green (CM/Cu-MOF) to black (CM/NC NWA). The introduction of NWA expanded the active surface area, prompted the uniform distribution of $\mathrm{Li}^{+}$, and provided more voids and nucleation sites to compensate for the volume change.

Fig. $5 f$ exhibits the detailed change in the XRD patterns of $\mathrm{CM}$, and the diffraction peak located before $40^{\circ}$ of the $\mathrm{CM} / \mathrm{Cu}$ MOF can be indexed to the Cu-MOF phase, which corresponds to that in a related study [54]. The disappearance of the $\mathrm{Cu}$ MOF diffraction peak on CM/NC NWA indicates the complete decomposition of the $\mathrm{Cu}-\mathrm{MOF}$ after annealing. The weak diffraction peak located at $\sim 36.5^{\circ}$ belongs to the (211) plane of $\mathrm{Cu}_{2} \mathrm{O}$, which is possibly due to the slight oxidation of the $\mathrm{CM}$ substrate surface during annealing. Additionally, a broad diffraction peak near $23^{\circ}$ indicates the presence of $\mathrm{C}$. The corresponding SEM elemental mapping images of CM/NC NWA (Fig. S14) show that CM/NC NWA are mainly composed of C, $\mathrm{N}, \mathrm{O}$, and $\mathrm{Cu}$, and the distribution of $\mathrm{C}$ element is consistent with the morphology of the nanowires. The TEM of NC NWA was performed to determine the composition of the MOFderived nanowires. As shown in Fig. S15, the surface of the nanowire has no granule or evident lattice fringe. Combined with the TEM elemental mapping of NC NWA (Fig. S15c-f), the NC NWA were $\mathrm{N}$-doped amorphous carbon nanowires with a thickness of $\sim 80 \mathrm{~nm}$. The XPS of CM/NC NWA (Fig. $5 \mathrm{~g}$ and Fig. S16) was measured to analyze the present state of the $\mathrm{C}$ and $\mathrm{N}$ elements in CM/NC NWA. The peaks at 284.8, 286.5, and $288.5 \mathrm{eV}$ for $\mathrm{C} 1 \mathrm{~s}$ indicate the presence of $\mathrm{C}-\mathrm{C}, \mathrm{C}-\mathrm{O}-\mathrm{C}$, and $\mathrm{O}-\mathrm{C}=\mathrm{O}$ (Fig. S16c), respectively, whereas the $\mathrm{N}$ 1s XPS spectrum shows three peaks at $398.8,400.5,401.6 \mathrm{eV}$, which correspond to the doping of pyridinic $\mathrm{N}$, pyrrolic $\mathrm{N}$, and graphitic $\mathrm{N}$ in $\mathrm{CM} / \mathrm{NC} \mathrm{NWA}$, respectively. The uniform distribution of $\mathrm{N}$ doping sites reduce the nucleation barriers of $\mathrm{Li}$ deposition on the $3 \mathrm{D}$ host and facilitate the rapid migration of $\mathrm{Li}^{+}$, thus achieving a uniform and dense $\mathrm{Li}$ deposition for dendrite-free $\mathrm{Li}$ electrode.

To explore the Li plating/stripping behavior and CE of the 3D $\mathrm{CM} / \mathrm{NC}$ NWA host, we assembled half cells by pairing a CM/NC NWA electrode with a $\mathrm{Li}$ foil electrode. Fig. 6i presents the voltage-capacity curves of plating $\mathrm{Li}$ metal with $10 \mathrm{~mA} \mathrm{~h} \mathrm{~cm}^{-2}$ capacity on $\mathrm{CM}$ and $\mathrm{CM} / \mathrm{NC} \mathrm{NWA}$ at $1 \mathrm{~mA} \mathrm{~cm}^{-2}$. In the initial plating profile, the potential gap from the lowest voltage to the subsequent voltage plateau is the nucleation overpotential, which reflects the heterogeneous nucleation barrier required for $\mathrm{Li}$ plating on the host. The CM/NC NWA electrode showed a reduced nucleation overpotential of $44.9 \mathrm{mV}$, which implies a small nucleation barrier on its surface, facilitating the uniform deposition of $\mathrm{Li}$ and suppressing $\mathrm{Li}$ dendrites. The corresponding deposition morphology evolution of Li metal on the CM/NC NWA electrode was characterized by SEM (Fig. 6a-h). The plated Li existed between the interstices and on the surface of the NWA. With the augmented plating capacity of $\mathrm{Li}$, the initial carbon nanowires increased in diameter due to the embedding of the deposited $\mathrm{Li}$, whereas the number of coarse whisker-like Li deposited on the surface increased. These surface-deposited whisker Li gradually fused together and spread into the pores until they filled the entire $\mathrm{Cu}$ network, which formed a uniform and flat Li deposition plane with no dendrite. Fig. S17 shows the morphological evolution of CM with the same amount of $\mathrm{Li}$ deposition, and the results show that the deposition of $\mathrm{Li}$ on CM is not uniform, and several Li dendrites exist at the junctions of the $\mathrm{Cu}$ network, which exacerbate the subsequent inhomogeneous stripping/plating of Li. The structural stability of the CM/NC NWA electrode was probed by stripping off all the originally plated $\mathrm{Li}\left(10 \mathrm{~mA} \mathrm{hm}^{-2}\right)$. As shown in Fig. S18, the reappearance of the NWA structure on $\mathrm{CM} / \mathrm{NC}$ NWA after plating/stripping provides solid evidence for the good structural stability of the CM/NC NWA host, which can resist large volume changes during lithium plating/stripping. In addition, almost no significant amounts of lithium residues were present on the $\mathrm{CM} / \mathrm{NC}$ NWA electrode. By contrast, numerous lithium residues remained on the CM (Fig. S19). The $\mathrm{CE}$ values of the $\mathrm{CM}$ and $\mathrm{CM} / \mathrm{NC}$ NWA electrodes were measured in half cells at $2 \mathrm{~mA} \mathrm{~cm}^{-2}$ and $10 \mathrm{~mA} \mathrm{~h} \mathrm{~cm}^{-2}$, and the comparative results are illustrated in Fig. 6j. The CM/NC NWA electrode can maintain a stable cyclic property with an average $\mathrm{CE}$ value of $97.95 \%$ for more than 400 cycles, whereas the CM electrode can operate steadily for 310 cycles, followed by a rapid drop in CE values to below 80\%. In addition, the CM@Li and CM/NC NWA@Li electrodes were fabricated by depositing Li with $10 \mathrm{~mA} \mathrm{~h} \mathrm{~cm}^{-2}$ capacity into the host. Fig. 6k shows the cyclic property of the prepared composite $\mathrm{Li}$ anodes in symmetrical cells. The CM@Li composite electrode revealed a sharp increase in overpotential after cycling for $40 \mathrm{~h}$ at a high current density of $10 \mathrm{~mA} \mathrm{~cm}^{-2}$ with an areal capacity of $1 \mathrm{~mA} \mathrm{~h} \mathrm{~cm}^{-2}$, whereas the CM/NC NWA@Li composite electrode exhibited a prolonged cyclic life for over $180 \mathrm{~h}$ with a smaller voltage hysteresis. Fig. S20 displays the EIS curves of the CM@Li and CM/ NC NWA@Li composite electrodes before and after 100 cycles. The CM/NC NWA@Li composite electrode showed a lower $R_{\mathrm{ct}}$ than the CM@Li composite electrode before and after 100 cycles. Thus, the CM/NC NWA@Li composite electrode had an enhanced electronic conductivity for rapid $\mathrm{Li}^{+}$transfer kinetics. In addition, the morphology of the CM/NC NWA@Li composite electrode after the 100th cycle at $10 \mathrm{~mA} \mathrm{~cm}^{-2}$ and $1 \mathrm{~mA} \mathrm{~h} \mathrm{~cm}^{-2}$ was observed using SEM (Fig. S21). The CM/NC NWA@Li composite electrode maintained a flat and homogenous Li layer without cracking or bulging after cycling, which indicates the capability of CM/NC NWA host in suppressing Li dendrites and volume change in repeated $\mathrm{Li}$ stripping/plating. The excellent electrochemical performance of the $\mathrm{Cu}-\mathrm{MOF}$-derived $\mathrm{CM} / \mathrm{NC}$ NWA host in both half-cells and symmetric cells demonstrates the universality of the current MOF-derived strategy for the construction of high-performance composite lithium anodes, which can be extended to other metal-based substrates for insitu growth of diverse and controllable array structures on the 3D host.

To further verify the potential of composite lithium anodes for commercial applications, we measured the relevant electrochemical performance in full cells with the LFP cathode. At $1 \mathrm{C}$, the Li||LFP and CC@ZnO/NC@Li||LFP cells exhibited capacities above $135 \mathrm{mAhg}^{-1}$ in the 1st cycle, whereas the CC@ZnO/ NC@Li||LFP cell showed a smaller voltage hysteresis (Fig. 7a, b). In terms of long cyclic property, the CC@ZnO/NC@Li||LFP cell can run steadily for 400 cycles at $1 \mathrm{C}$ with less capacity loss (Fig. S22) and is thus significantly better than the Li||LFP cell (which can run stably for 100 cycles). During cycling with an increased rate of 5C, the CC@ZnO/NC@Li||LFP cell still 



Figure 6 SEM images of CM/NC NWA host at different magnifications after depositing Li metal of different capacities: (a, b) 1, (c, d) 2, (e, f) 5, and $(\mathrm{g}, \mathrm{h}) 10 \mathrm{~mA} \mathrm{~h} \mathrm{~cm}^{-2}$; (i) plating profiles of Li on CM and CM/NC NWA host; (j) CE comparison in CM and CM/NC NWA half cells at $2 \mathrm{~mA} \mathrm{~cm}{ }^{-2}$ and $2 \mathrm{~mA} \mathrm{~h} \mathrm{~cm}^{-2}$; (k) cycling property of the CM@Li and CM/NC NWA@Li composite electrodes in symmetric cells at $10 \mathrm{~mA} \mathrm{~cm}$ and $1 \mathrm{mAh} \mathrm{cm}^{-2}$.

exhibited high cyclic stability with a capacity of $113 \mathrm{~mA} \mathrm{~h}^{-1}$ retained after 800 cycles, whereas the capacity of the bare Li||LFP cell decayed rapidly after 300 cycles (Fig. 7c). The rapid capacity fade in bare Li||LFP cells may be due to the accumulation of $\mathrm{Li}$ dendrites on the surface of the Li electrode, leading to the depletion of the active capacity of the electrode. The corresponding rate performance (Fig. $7 \mathrm{~d}$ ) illustrates that the capacity of CC@ZnO/NC@Li||LFP cell can still reach a capacity of
$127 \mathrm{~mA} \mathrm{~h} \mathrm{~g}^{-1}$ at $5 \mathrm{C}$ with a progressive increase in rate, whereas a value of $92 \mathrm{~mA} \mathrm{~h} \mathrm{~g}^{-1}$ is observed for the bare Li||LFP cell. Fig. S23 shows the electrochemical performance of the CM/NC NWA@Li||LFP full cells assembled with Cu-MOF-derived metal-based host. The CM/NC NWA@Li||LFP still showed a high capacity of $125.7 \mathrm{~mA} \mathrm{~h} \mathrm{~g}^{-1}$ after 250 cycles at $1 \mathrm{C}$, presenting excellent cycling stability. The enhanced electrochemical performance of the CC@ZnO/NC@Li||LFP cell and CM/NC 
NWA@Li||LFP further confirms the superiority and feasibility of $\mathrm{Li}$ anodes composited with Li metal and MOF-derived 3D stable host prepared by combining Li metal with the MOF-derived 3D stable host.

CC@ZnO/NC@Li||LFP pouch cells were fabricated to verify the flexibility of CC@ZnO/NC@Li. At $0.2 \mathrm{C}$, the flexible CC@ZnO/NC@Li||LFP cell showed a high initial discharge capacity of $154.5 \mathrm{~mA} \mathrm{~h} \mathrm{~g}^{-1}$. After increasing the rate to $0.5 \mathrm{C}$ and continuous running until the 40th cycle, a capacity retention of 94.8\% was achieved (Fig. 8a, b). In addition, the CC@ZnO/ NC@Li||LFP pouch cell can power the light-emitting diode at different bending angles from $0^{\circ}$ to $180^{\circ}$ (Fig. 8c), proving its superior flexibility. This CC@ZnO/NC@Li composite anode with a binder-free feature showed stable electrochemical per-
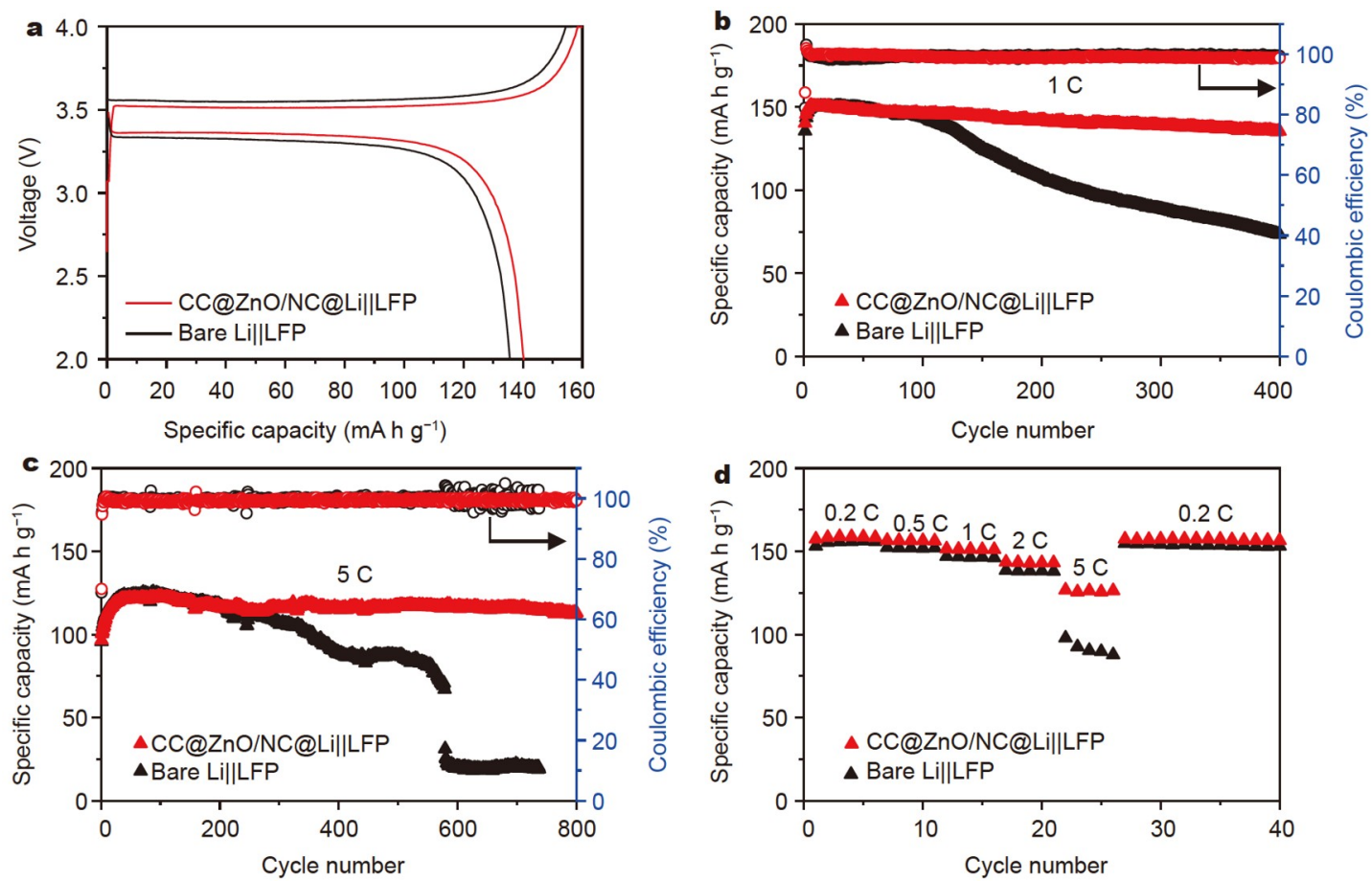

Figure 7 Electrochemical performance comparison of the CC@ZnO/NC@Li||LFP and Li||LFP full cells: (a) typical charge/discharge profiles at 1 C; cycling performances at (b) $1 \mathrm{C}$ and (c) $5 \mathrm{C}$; (d) rate capability at different rates from 0.2 to $5 \mathrm{C}$.
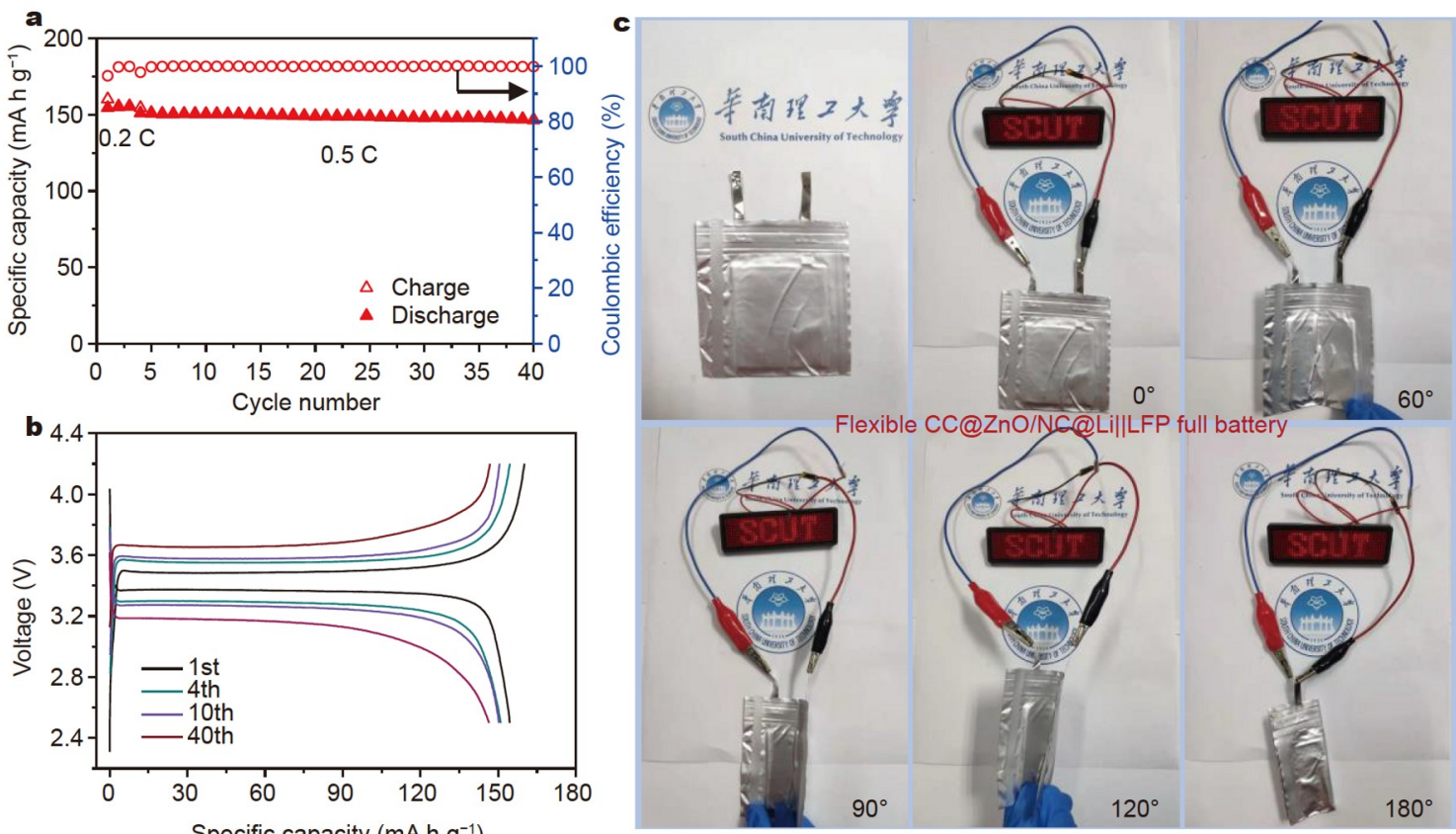

Figure 8 Electrochemical performance and flexibility measurement of the CC@ZnO/NC@Li||LFP pouch cell: (a) cycling stability at 1C and (b) the corresponding discharging/charging curves; (c) measurement of the CC@ZnO/NC@Li||LFP pouch cell lighting up LEDs at different bending angles. 
formance and excellent flexibility, which are promising for applications in flexible high-energy-density batteries.

\section{CONCLUSIONS}

A lithiophilic MOF-derived $\mathrm{ZnO} / \mathrm{NC}$, nanosheet-modified, and CC-entrapped molten $\mathrm{Li}$ was designed as a dendrite-free $\mathrm{Li}$ metal anode. Benefiting from the synergy of 3D conductive carbon fibers and lithiophilic $\mathrm{ZnO} / \mathrm{NC}$ nanosheets, the proposed CC@ZnO/NC@Li electrode has high mechanical stability that ensures electrode integrity and restrains electrode volume change during cycling and a high Li affinity that promotes homogeneous Li plating/stripping and ensures a rapid charge transfer, thereby suppressing dendrite growth and $\mathrm{Li}$ pulverization. This unique CC@ZnO/NC@Li electrode attained superior cyclic stability and prolonged lifespan with low overpotentials at different current densities. The CC@ZnO/NC@Li\| LFP full cells demonstrated superior cyclic property and rate capability than bare Li foil anodes. In addition, MOF-derived 3D metal-based CM/NC NWA can be used as the Li host to fabricate a stable composite $\mathrm{Li}$ anode via electrodeposition, and this Li electrode exhibited an excellent long-cycle performance during battery operation. This study proves that the introduction of lithiophilic MOF-derived materials on 3D current collectors has a positive effect on achieving the practical applications of composite Li anodes with a high energy density. Further, stable composite $\mathrm{Li}$ anodes can be fabricated via electrodeposition.

\section{Received 12 May 2021; accepted 4 August 2021;}

published online 10 September 2021

1 Dunn B, Kamath H, Tarascon JM. Electrical energy storage for the grid: A battery of choices. Science, 2011, 334: 928-935

2 Xie J, Lu YC. A retrospective on lithium-ion batteries. Nat Commun, 2020, 11: 2499

3 Chu S, Majumdar A. Opportunities and challenges for a sustainable energy future. Nature, 2012, 488: 294-303

4 Li F, Liu Z, Shen J, et al. A nanorod-like Ni-rich layered cathode with enhanced $\mathrm{Li}^{+}$diffusion pathways for high-performance lithium-ion batteries. J Mater Chem A, 2021, 9: 2830-2839

5 Whittingham MS. History, evolution, and future status of energy storage. Proc IEEE, 2012, 100: 1518-1534

6 Yang H, Guo C, Naveed A, et al. Recent progress and perspective on lithium metal anode protection. Energy Storage Mater, 2018, 14: 199221

7 Shen $\mathrm{X}$, Liu $\mathrm{H}$, Cheng XB, et al. Beyond lithium ion batteries: Higher energy density battery systems based on lithium metal anodes. Energy Storage Mater, 2018, 12: 161-175

8 Wang Z, Xu X, Ji S, et al. Recent progress of flexible sulfur cathode based on carbon host for lithium-sulfur batteries. J Mater Sci Tech, 2020, 55: 56-72

9 Wang Z, Shen J, Liu J, et al. Self-supported and flexible sulfur cathode enabled via synergistic confinement for high-energy-density lithiumsulfur batteries. Adv Mater, 2019, 31: 1902228

10 Cheng XB, Zhang R, Zhao CZ, et al. Toward safe lithium metal anode in rechargeable batteries: A review. Chem Rev, 2017, 117: 10403-10473

11 Chen Y, Luo Y, Zhang $\mathrm{H}$, et al. The challenge of lithium metal anodes for practical applications. Small Methods, 2019, 3: 1800551

12 Yasin G, Arif M, Mehtab T, et al. Understanding and suppression strategies toward stable Li metal anode for safe lithium batteries. Energy Storage Mater, 2020, 25: 644-678

13 Liu B, Zhang JG, Xu W. Advancing lithium metal batteries. Joule, 2018, 2: 833-845

14 Shi Q, Zhong Y, Wu M, et al. High-capacity rechargeable batteries based on deeply cyclable lithium metal anodes. Proc Natl Acad Sci USA, 2018, 115: 5676-5680

15 Liu Y, Lin D, Li Y, et al. Solubility-mediated sustained release enabling nitrate additive in carbonate electrolytes for stable lithium metal anode. Nat Commun, 2018, 9: 3656

16 Li W, Yao H, Yan K, et al. The synergetic effect of lithium polysulfide and lithium nitrate to prevent lithium dendrite growth. Nat Commun, 2015, 6: 7436

17 Cheng XB, Zhang R, Zhao CZ, et al. A review of solid electrolyte interphases on lithium metal anode. Adv Sci, 2016, 3: 1500213

18 Yang T, Sun Y, Qian T, et al. Lithium dendrite inhibition via 3D porous lithium metal anode accompanied by inherent SEI layer. Energy Storage Mater, 2020, 26: 385-390

19 Li NW, Yin YX, Yang CP, et al. An artificial solid electrolyte interphase layer for stable lithium metal anodes. Adv Mater, 2016, 28: 1853-1858

20 Lee DJ, Lee H, Kim YJ, et al. Sustainable redox mediation for lithiumoxygen batteries by a composite protective layer on the lithium-metal anode. Adv Mater, 2016, 28: 857-863

21 Yang $\mathrm{Q}$, Cui $\mathrm{M}, \mathrm{Hu}$ J, et al. Ultrathin defective C-N coating to enable nanostructured Li plating for Li metal batteries. ACS Nano, 2020, 14: 1866-1878

22 Huang M, Yao Z, Wu Q, et al. Robustness-heterogeneity-induced ultrathin 2D structure in Li plating for highly reversible Li-metal batteries. ACS Appl Mater Interfaces, 2020, 12: 46132-46145

23 Wang SH, Yin YX, Zuo TT, et al. Stable Li metal anodes via regulating lithium plating/stripping in vertically aligned microchannels. Adv Mater, 2017, 29: 1703729

24 Liu T, Chen S, Sun W, et al. Lithiophilic vertical cactus-like framework derived from $\mathrm{Cu} / \mathrm{Zn}$-based coordination polymer through in situ chemical etching for stable lithium metal batteries. Adv Funct Mater, 2021, 31: 2008514

25 Li Q, Zhu S, Lu Y. 3D porous Cu current collector/Li-metal composite anode for stable lithium-metal batteries. Adv Funct Mater, 2017, 27: 1606422

26 Luo Z, Liu C, Tian Y, et al. Dendrite-free lithium metal anode with lithiophilic interphase from hierarchical frameworks by tuned nucleation. Energy Storage Mater, 2020, 27: 124-132

27 Huang S, Chen L, Wang T, et al. Self-propagating enabling high lithium metal utilization ratio composite anodes for lithium metal batteries. Nano Lett, 2021, 21: 791-797

28 Jiang J, Pan Z, Kou Z, et al. Lithiophilic polymer interphase anchored on laser-punched $3 \mathrm{D}$ holey $\mathrm{Cu}$ matrix enables uniform lithium nucleation leading to super-stable lithium metal anodes. Energy Storage Mater, 2020, 29: 84-91

29 Lu LL, Ge J, Yang JN, et al. Free-standing copper nanowire network current collector for improving lithium anode performance. Nano Lett, 2016, 16: 4431-4437

30 Huang Z, Zhang C, Lv W, et al. Realizing stable lithium deposition by in situ grown $\mathrm{Cu}_{2} \mathrm{~S}$ nanowires inside commercial $\mathrm{Cu}$ foam for lithium metal anodes. J Mater Chem A, 2019, 7: 727-732

31 Feng YQ, Zheng ZJ, Wang CY, et al. A super-lithiophilic nanocrystallization strategy for stable lithium metal anodes. Nano Energy, 2020, 73: 104731

32 Sun B, Li P, Zhang J, et al. Dendrite-free sodium-metal anodes for highenergy sodium-metal batteries. Adv Mater, 2018, 30: 1801334

33 Lin D, Liu Y, Liang Z, et al. Layered reduced graphene oxide with nanoscale interlayer gaps as a stable host for lithium metal anodes. Nat Nanotech, 2016, 11: 626-632

34 Zhou T, Shen J, Wang Z, et al. Regulating lithium nucleation and depositionvia MOF-derived Co@C-modified carbon cloth for stable Li metal anode. Adv Funct Mater, 2020, 30: 1909159

35 Lin D, Liu Y, Cui Y. Reviving the lithium metal anode for high-energy batteries. Nat Nanotech, 2017, 12: 194-206

36 Zheng ZJ, Ye H, Guo ZP. Recent progress in designing stable composite lithium anodes with improved wettability. Adv Sci, 2020, 7: 2002212

37 Chen K, Pathak R, Gurung A, et al. A copper-clad lithiophilic current collector for dendrite-free lithium metal anodes. J Mater Chem A, 2020, 8: 1911-1919

38 Zhao F, Zhou X, Deng W, et al. Entrapping lithium deposition in lithiophilic reservoir constructed by vertically aligned $\mathrm{ZnO}$ nanosheets for dendrite-free Li metal anodes. Nano Energy, 2019, 62: 55-63

39 Fang Y, Zeng Y, Jin Q, et al. Nitrogen-doped amorphous Zn-carbon multichannel fibers for stable lithium metal anodes. Angew Chem Int Ed, 2021, 60: 8515-8520

40 Zhang Z, Wang J, Yan X, et al. In-situ growth of hierarchical N-doped 
CNTs/Ni foam scaffold for dendrite-free lithium metal anode. Energy Storage Mater, 2020, 29: 332-340

$41 \mathrm{Xu} \mathrm{X}$, Liu J, Liu J, et al. A general metal-organic framework (MOF)derived selenidation strategy for in situ carbon-encapsulated metal selenides as high-rate anodes for Na-ion batteries. Adv Funct Mater, 2018, 28: 1707573

$42 \mathrm{Wu} \mathrm{Q}$, Zhou X, Xu J, et al. Carbon-based derivatives from metalorganic frameworks as cathode hosts for Li-S batteries. J Energy Chem, 2019, 38: 94-113

43 Huang M, Yao Z, Yang Q, et al. Consecutive nucleation and confinement modulation towards Li plating in seeded capsules for durable Limetal batteries. Angew Chem Int Ed, 2021, 60: 14040-14050

44 Chen R, Yao J, Gu Q, et al. A two-dimensional zeolitic imidazolate framework with a cushion-shaped cavity for $\mathrm{CO}_{2}$ adsorption. Chem Commun, 2013, 49: 9500-9502

45 Wang L, Zhu X, Guan Y, et al. $\mathrm{ZnO} /$ carbon framework derived from metal-organic frameworks as a stable host for lithium metal anodes. Energy Storage Mater, 2018, 11: 191-196

46 Zhou Y, Zhao K, Han Y, et al. A nitrogen-doped-carbon/ZnO modified $\mathrm{Cu}$ foam current collector for high-performance $\mathrm{Li}$ metal batteries. J Mater Chem A, 2019, 7: 5712-5718

47 Zhang H, Liao X, Guan Y, et al. Lithiophilic-lithiophobic gradient interfacial layer for a highly stable lithium metal anode. Nat Commun, 2018, 9: 3729

48 Wang $\mathrm{X}$, Pan $\mathrm{Z}, \mathrm{Wu} \mathrm{Y}$, et al. Infiltrating lithium into carbon cloth decorated with zinc oxide arrays for dendrite-free lithium metal anode. Nano Res, 2018, 12: 525-529

49 Liu L, Yin YX, Li JY, et al. Free-standing hollow carbon fibers as highcapacity containers for stable lithium metal anodes. Joule, 2017, 1: 563575

50 Bieker G, Winter M, Bieker P. Electrochemical in situ investigations of SEI and dendrite formation on the lithium metal anode. Phys Chem Chem Phys, 2015, 17: 8670-8679

51 Xiao J. How lithium dendrites form in liquid batteries. Science, 2019, 366: 426-427

52 Li NW, Yin YX, Li JY, et al. Passivation of lithium metal anode via hybrid ionic liquid electrolyte toward stable Li plating/stripping. Adv Sci, 2017, 4: 1600400

53 Chi SS, Liu Y, Song WL, et al. Prestoring lithium into stable 3D nickel foam host as dendrite-free lithium metal anode. Adv Funct Mater, 2017, 27: 1700348

54 Yin D, Huang G, Na Z, et al. CuO nanorod arrays formed directly on $\mathrm{Cu}$ foil from MOFs as superior binder-free anode material for lithiumion batteries. ACS Energy Lett, 2017, 2: 1564-1570

Acknowledgements This work was supported by the National Natural Science Foundation of China (51771076 and 51621001), Guangdong "Pearl River Talents Plan" (2017GC010218), the R\&D Program in Key Areas of Guangdong Province (2020B0101030005), and Guangdong Basic and Applied Basic Research Foundation (2020B1515120049).

Author contributions Zeng $\mathrm{L}$ and Zhou $\mathrm{T}$ designed the samples and performed the experiments; Zeng L and Xu X wrote the manuscript; Li F and Zhang D were involved in the discussion and writing of the manuscript; Shen $\mathrm{J}$ assisted with the drawing of the flow chart. Liu J and Zhu M directed the project.

Conflict of interest The authors declare that they have no conflict of interest.

Supplementary information Supporting data are available in the online version of the paper.

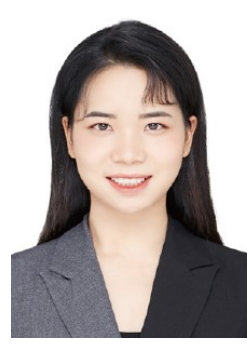

Liyan Zeng received her bachelor's degree from the Northeastern University in 2018. She is currently a postgraduate student under the supervision of Prof. Jun Liu at the South China University of Technology (SCUT). Her research interests are electrode materials for sodium-ion batteries and lithium metal anode batteries.



Jun Liu is a professor of material science and engineering at SCUT. He received his $\mathrm{PhD}$ degree in chemical engineering and technology at Dalian University of Technology in 2011. His current research interests mainly include high-energy density $\mathrm{Li} / \mathrm{Na}$ ion batteries, all-solid-state batteries, lithium sulfur batteries, and novel energy devices.

\section{采用通用MOF衍生路线构建无枝晶锂金属负极用亲 锂3D骨架}

曾立艳, 周婷, 许希军, 李方坤, 沈家东, 张德超, 刘军*, 朱敏

摘要 对高续航里程车型的追求使锂金属电池(LMBs)再次引起研究人 员的关注. 然而, 锂金属负极在循环过程中会出现不可控的锂枝晶形成 和无限大的体积变化, 阻碍了其实际应用. 为了解决这些棘手问题, 本 文采用一种金属有机框架(MOF)衍生路线，在不同的基底(如碳布和铜 网)上通用地构建出亲锂三维骨架，以实现无枝晶锂金属负极. 作为一 个典型的例子. $\mathrm{MOF}$ 衍生的 $\mathrm{ZnO} / \mathrm{NC}$ (氮掺杂碳)纳米片修饰的三维碳布 (CC) 被较好地构建为亲锂宿主, 用于灌注熔融锂 (标记为 $\mathrm{CC} @ \mathrm{ZnO} /$ $\mathrm{NC} @ \mathrm{Li}$ ). 得益于亲锂的 $\mathrm{N}$ 官能团和LiZn合金, 制备的CC@ZnO/NC@Li 复合负极极大地促进了锂的均匀分布, 使电极呈现为无枝晶形貌. 同时, 三维导电碳骨架可增强反应动力学并缓冲电极的体积变化. 因此, $\mathrm{CC} @ \mathrm{ZnO} / \mathrm{NC} @ \mathrm{Li}$ 复合负极具有延长的循环寿命, 可在 $5 \mathrm{~mA} \mathrm{~cm}^{-2}$ 下以 $19 \mathrm{mV}$ 的低过电位稳定循环超过 1000 次. 与 $\mathrm{LiFePO}_{4}$ 正极相匹配时, $\mathrm{CC} @ \mathrm{ZnO} / \mathrm{NC} @ \mathrm{Li}$ 复合负极在全电池系统中也表现出了优异的电化学性 能. 这种通用策略可为设计金属锂的多功能亲锂性三维宿主拓宽途径. 